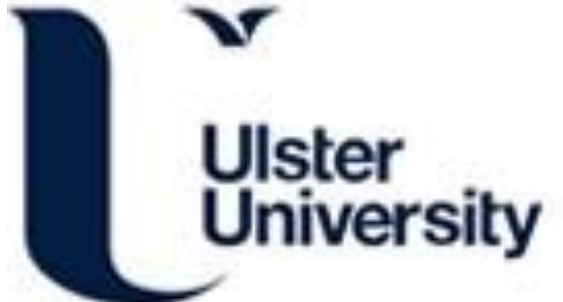

\section{The linguistic implications of academic performance indicators: General trends and case study}

Gazzola, M. (2012). The linguistic implications of academic performance indicators: General trends and case study. International Journal of the Sociology of Language, 2012(261), 131-156. https://doi.org/10.1515/ijsl-20120043

Link to publication record in Ulster University Research Portal

\section{Published in:}

International Journal of the Sociology of Language

Publication Status:

Published (in print/issue): 07/07/2012

DOI:

10.1515/ijsl-2012-0043

\section{Document Version}

Publisher's PDF, also known as Version of record

\section{General rights}

Copyright for the publications made accessible via Ulster University's Research Portal is retained by the author(s) and / or other copyright owners and it is a condition of accessing these publications that users recognise and abide by the legal requirements associated with these rights.

\section{Take down policy}

The Research Portal is Ulster University's institutional repository that provides access to Ulster's research outputs. Every effort has been made to ensure that content in the Research Portal does not infringe any person's rights, or applicable UK laws. If you discover content in the Research Portal that you believe breaches copyright or violates any law, please contact pure-support@ulster.ac.uk. 


\section{The linguistic implications of academic performance indicators: general trends and case study}

MICHELE GAZZOLA*

Abstract

This article analyzes the new system of indicators adopted in Italy to evaluate universities' research activities, and it shows that this system provides an implicit structure of economic incentives which de facto is likely to favor the use of English in scientific communication. This is due, among other things, to the use of bibliometric indicators and databases skewed in favor of English. This article also analyzes the rising phenomenon of programs taught entirely in English in Italian universities, showing that the introduction of programs in English does not seem to respond to a real demand by students or to a demand for language skills in the Italian labor market. Rather, it is related to the use of the number of foreign students as an indicator of university performance. The focus of the article is on the respective use of Italian and English in Italian universities, but general remarks are also relevant to other countries and the European Union as a whole. This article emphasizes the effects of academic performance indicators on linguistic diversity and thus their role as a language policy tool. In addition, it addresses the question of the quality of indicators currently employed.

Keywords: language policy; research assessment; journal impact factor; bibliometric indicators; international student mobility; university rankings.

\section{Introduction}

The role of higher education in influencing economic growth has become stronger as a result of several structural changes that have taken place in the economies of developed countries during the last two decades. Information, technology, research and learning have gradually become the strongest drivers of productivity and economic growth (OECD 1996). This phenomenon is often referred to as the "emergence of the knowledge-based economy". 1 
My reflections of the emergence of the knowledge-based economy have led to the conclusion that its influence on national higher education systems has been twofold. First, it has stressed the role of evaluation. A possible strategy to improve universities' results in research and teaching consists in introducing a certain degree of selectivity in the allocation of public funding. In other words, a given share of resources can be allocated on a competitive basis according to the outcomes achieved by universities, captured through appropriate performance indicators.

A second consequence regards the increasingly strategic importance of attracting highly-skilled individuals from other countries (cf. OECD 2008b). This implies, among other things, the implementation of a series of immigration policies aimed at supporting the international mobility of students and researchers, or more specifically of the "brightest students and researchers" (OECD 2008b). The European Union (EU) strategy for higher education provides an example of such policies. ${ }^{2}$ Without entering into too much detail, suffice it to say that the goal of this strategy is to create three common European areas for higher education, research and lifelong learning. This strategy is carried out through different measures aiming at, among other things, fostering the mobility of students, and harmonizing undergraduate and postgraduate degrees in European countries. This is the goal of what is known as "the Bologna process", named after the Bologna declaration, signed in 1999 by ministers in charge of higher education of several European countries.

The focus of the article is on the Italian case, but general remarks are also relevant to other countries and the European Union as a whole. The recent reform of public funding to universities in Italy, and the increasing attention paid by Italian universities to the international mobility of students, in fact, should be interpreted in the light of the international trends just presented. According to several observers (cf. various contributions in Maccacaro 2007; Perotti 2008), the Italian university lags behind the higher education systems of comparable OECD countries (see Appendix for abbreviations), and this negatively affects Italy's competitiveness and economic growth (Tabellini 2007). The "quality of scientific publications", "position of Italian universities in international rankings", "percentage of foreign students enrolled", are some examples of indicators used in public debate to compare the Italian university system to others. ${ }^{3}$

This article critically discusses the effects of these reforms on the Italian linguistic environment, focusing in particular on the language policies adopted by public authorities at different levels. Section 2 discusses the potential impact of evaluation of universities for funding purposes on the respective use of Italian and English in primary scientific communication, ${ }^{4}$ that is, specialized communication between experts. I focus in particular on academic publications. Section 3 focuses on policies aimed at increasing international students' 
mobility and on their effects on secondary scientific communication, that is, communication addressed to the layperson, for example students or general public. I focus more specifically on teaching. Section 4 summarizes and concludes.

\section{The linguistic implications of research performance evaluation}

\subsection{A reform based on performance indicators}

The first law promulgated by the Italian Parliament in 2009 (Law No. 1/2009) introduces two important innovations for Italian universities, which are predominantly public and funded by the State. Article 1 (paragraph 7) provides that the recruitment of "ricercatori" (lecturers) ${ }^{5}$ has to be linked to "internationally acknowledged parameters". Article 2 provides that a share not lower than $7 \%$ of State funding to universities has to be allocated on the basis of indicators reflecting quality of scientific research (2/3 of the share), and quality of programs and results of educational processes $(1 / 3)$. It is also provided that this share will be increased over the years. In absolute terms, $7 \%$ of State funding to universities is equivalent to $€ 523.5$ million for 2009-2010 (MIUR 2009a).

Both Articles 1.7 and 2, therefore, refer to the concept of performance indicator. An indicator can be defined as a "measurement of an objective to be met, a resource mobilised, an effect obtained, a gauge of quality or a context variable. An indicator produces quantified information with a view to helping actors concerned with public interventions to communicate, negotiate or make decisions" (European Commission [1999: 17], my emphasis). Generally speaking, a good indicator should, among other desirable properties, display validity and reliability (cf. European Commission [1999: 221-222] for an overview). An indicator is valid if it avoids ambiguities. Hence, the correspondence between the indicator and the object it is deemed to reflect (e.g. scientific quality) ought to be as clear as possible. An indicator is reliable if two different persons taking the same measurement under identical conditions obtain identical indicator values, obviously within a certain margin of error.

It is important to be aware that in some cases and perhaps in all cases indicators are not neutral tools used for representing a reality which exists independently from the indicators themselves. The use of indicators for evaluation can modify reality, since they can have a direct impact on actors' behavior, including language choices. In other words, agents may do something that they would not have done otherwise to cause a change in the value of an indicator towards a desired direction. In some cases the change in actors' behavior is precisely the goal of the policy maker, and indicators can provide an appropriate 
incentive for actors. However, the use of indicators can also have adverse effects, for example if it causes the actors to work on improving the indicator rather than the result (European Commission 1999: 223-225).

The Italian Minister of Education, University and Research - MIUR, following its acronym in Italian - is responsible for implementing Law No. $1 / 2009$. MIUR provisions do not include any specific norm related to language (MIUR 2009a; 2009b). However, on the basis of the empirical evidence available, I show that current norms provide an implicit structure of incentives which de facto is likely to favor the use of English in primary scientific communication (in particular in academic publications), among other things, as a result of the use of bibliometric indicators - and in particular the journal impact factor - for evaluative purposes. Hence, it is useful to start this section with a brief discussion of bibliometric indicators and their effects on linguistic diversity.

\subsection{The role of bibliometric indicators in evaluation}

2.2.1. The journal impact factor: validity, language bias and evaluation outcomes. The journal impact factor (JIF) - defined as the ratio between the number of citations a journal receives in year $\mathrm{X}$ to articles published in the two previous years and the number of articles published in that journal in those same years - is a bibliometric indicator developed in the US at the end of 1920s for guiding the journal subscriptions strategies of American universities librarians. ${ }^{6}$ The JIF has gradually emerged as a tool used at an international level for ranking academic journals since the 1970s as a result of the commercial activity of the Institute for Scientific Information (ISI) - now Thompson Reuters. Often bibliometric indicators have been presented as objective tools (as opposed to subjective peer reviewing) for comparing universities and countries with respect to the quality of their scientific research, and this can explain the recent sharp increase in the interest of policy makers and public opinion for bibliometrics (Moed 2005).

It would exceed the limits of this article to discuss all the technical and epistemological shortcomings of the JIF, ${ }^{7}$ but let us point out some of its most evident weakness. First, the value of the JIF is strongly dependent on subject fields (Amin and Mabe 2000). Secondly, the window of measurement used (two years) is arbitrary. Thirdly, the value of the JIF is influenced by the type of article and journal. State-of-the-art reviews, for example, inflate the JIF because on average they are more often quoted. Moreover, journals publishing short papers ("letters") have usually a higher immediacy. In the fourth place, no difference is made between positive citations and highly controversial or negative citations. ${ }^{8}$ In addition, the JIF can be manipulated by actors. In some 
cases, the use of the JIF has influenced the publication strategies of journal editors, who can encourage authors to cite articles already published in the same journal where authors have submitted their paper precisely to increase its impact factor (Archambault and Larivière 2009: 636; Weingart 2005: 127). This may seriously hamper the objectivity of the JIF as a tool for evaluation. Besides, it is also worth noticing that the process of article selection in academic journals is ultimately based on peer reviewing, and therefore, on subjective judgments (Weingart 2005: 122). Finally, the journal impact factor is not statistically representative of the impact of single articles, that is, of the scientific products evaluated. For biochemical journals between 1983 and 1984, for example, Seglen (1997) shows that the most cited $50 \%$ of the articles account for $90 \%$ of the citations, and the most cited $15 \%$ of the articles account alone for $50 \%$ of the citations. For these reasons, the JIF is not a valid indicator for scientific quality and it should not be used as proxy for it. According to Moed (2005: 20), for example, the JIF is a "citations measure impact rather then quality", Weingart (2005: 126) argues that the JIF could simply reflect a journal's visibility.

However, the most controversial issues related to bibliometric indicators regard their use in international comparisons of countries' scientific performance. Bibliometric indicators employed in these comparisons are usually based exclusively on ISI citation indexes - that is, the various information products based on citation indexing of academic literature produced by ISI such as the Science Citation Index, the Social Sciences Citation Index, and the Arts \& Humanities Citation Index - which are notoriously biased in favor of journals in English, while journals in other languages are usually insufficiently covered, especially in social and human sciences (cf., among others, Archambault and Larivière 2009; Bordons et al. 2002; Seglen 1997). This problem is sometimes called "language bias". The language coverage choices of new databases such as Elsevier's Scopus or Google Scholar could have an impact on the language bias. However, ISI citation indexes are currently still the most frequently used database worldwide for bibliometric analysis and the evaluation of research activities.

The effects of the language bias on international comparisons between countries (and universities) have been analyzed empirically by different authors. Van Leeuwen et al. (2001), for example, present an impact analysis of the scientific publications produced between 1981 and 1998 by the USA, the UK, Switzerland, France and Germany in the field of medical research. They use the ratio CPP/FCSm as an impact indicator. ${ }^{9}$ Results are presented in Figure 1.

The chart at the top of Figure 1 reports the results of impact analysis based on a dataset of journals in medical research covered by Science Citation Index. Only publications in English are considered. The chart at the bottom of Figure 1 reports the results of the same impact analysis based on the same journal 

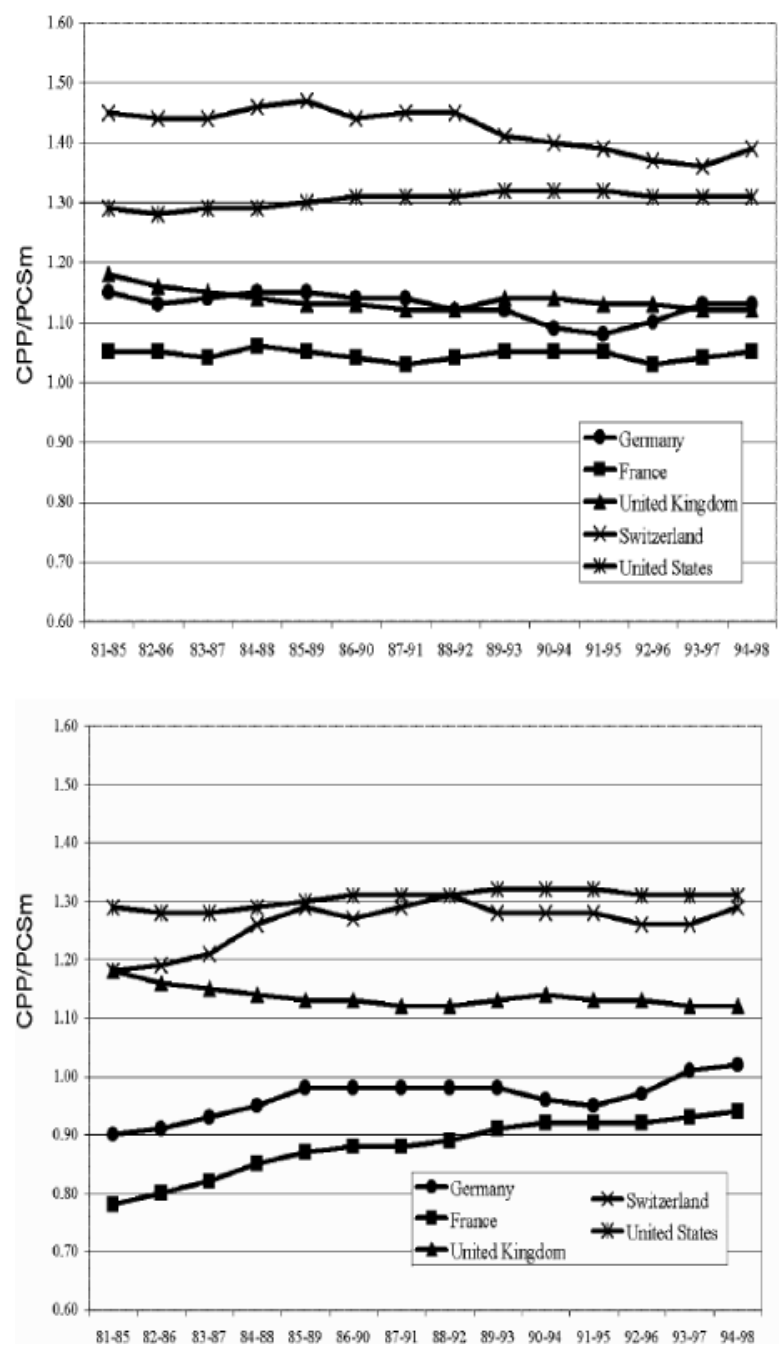

Figure 1. Effects of language bias on international comparisons (medical research publications, 1981-1998). Source: reproduced from Van Leeuwen et al. (2001: 340 -341, Figures 3 and 4), with kind permission from Springer Science+Business Media B.V.

dataset, but including publications in other languages than English covered by the Science Citation Index. Figure 1 shows that the relative position of Switzerland, France and Germany significantly worsens once publications in ISI-covered journals from Swiss, French and German medical scientists in other languages than English are included. This is due to the fact that, on aver- 
age, journals not in English are less often cited. Hence, the inclusion of publications in these journals in the dataset decreases the ranking of non-English speaking countries.

In other words, publications in languages other than English "within the boundaries of the Science Citation Index, seriously (but 'artificially') 'dilute' the impact score of these major scientific nations" (Van Leeuwen et al. 2001: 345). In addition, the same authors observe a similar effect when extending the analysis to include more fields (i.e. natural and technical sciences) and more countries, namely, Italy, Spain and Japan. Moed's analysis (2002) for China in the period 1980-1999 are consistent with Van Leeuwen et al.'s results. Using the same methodology employed by Van Leeuwen et al., Moed (2002) shows that including Chinese national journals in bibliometric analysis based on ISI citation indexes decreases the impact score of China's scientific research in several disciplines. Recent empirical evidence confirms the existence of a clear language bias in international comparisons, which is particularly detrimental to the ranking of French and German universities (Van Raan et al. 2011).

This could lead to the paradoxical conclusion that journals not in English should be excluded from comparisons between countries. However, as Van Leeuwen et al. note, this would not solve the problem, since "the exclusion of the non-English journal publications will, in combination with for example demographic data, decrease both the number of publications per capita as well as the total impact per capita (i.e., not field-normalised)" (2001: 345).

Some authors, however, tend to minimize the language bias of ISI citations indexes..$^{10}$ One could argue that these empirical findings can be explained by the fact that non-Anglophone scientists tend to publish their "best" articles in international influential journals in English and their "worst" articles in national journals in other languages, which therefore are less cited (this would explain a low JIF). Obviously, it would be misleading to deny that many of the most prestigious academic journals publish in English. However, this argument is not convincing because of potential circularity (cf. the statement "a journal is good because it has a high impact factor, and the reason why it has a high impact factor is that it is a good journal"). This is due to the fact that the quality of a journal is a priori defined precisely in terms of JIF.

A first problem is that the impact factor of a journal depends on the capability of researchers to read the language in which the journal is written, and therefore the demographic size of the national researchers' community and the skills of researchers in foreign languages are likely to play a role in the determination of the value of the JIF. ${ }^{11}$ The empirical importance of this demographic effect is a separate question, but it is certainly not systematically related to journals' quality. Secondly, the JIF depends on the choices of ISI as to which journals to cover. If the journals of a given linguistic area are not covered, the JIF of these journals is zero. Moreover, the computation of the JIF 
of an ISI-covered journal not in English does not include citations of this journal made in journals not indexed by ISI (in particular other journals not in English). This can negatively and artificially affect the JIF of these ISI-covered journals and consequently the ranking of non-English-speaking countries.

Despite all of its shortcomings, several countries employ the JIF to a different extent, in evaluating universities' research activities, for example, Spain (Bordons et al. 2002), Canada, Hungary, and the Nordic countries (Seglen 1997; Weingart 2005). In China, Pakistan and South Korea the JIF is also used for the evaluation of individual researchers (Fuyuno and Cyranoski 2006). For lack of something better, the JIF is often used for comparing a country's research results with other states with a view to obtaining useful information for setting national research policies. Although the language bias is often mentioned as a problem (e.g. Bordons et al. 2002), to my knowledge there is no systematic attempt to correct it.

Let us now turn to the impact of the ISI-based JIF on linguistic diversity in scientific communication. Generally speaking, the most remarkable effect related to the use of the JIF is that it has contributed to increasing the speed of convergence towards the use English in academic publications (Ammon 2006; Archambault and Larivière 2009). Carli and Calaresu (2003: 45-60), for example, show that the JIF has played a central role in explaining the (partial or total) switch to English of different Italian academic journals in medicine in the 1990s. It is worth noting, however, that there is no necessary relation between the choice of a journal to switch to English and an increase of its JIF. Results of empirical research carried out by Bracho-Riquelme et al. (1999) between 1974 to 1992 on the prestigious Pasteur Institute journals, for example, show that the change from French to English has had no effect on the impact factor and ranking of these journals among journals of the same field.

The inclusion of the JIF in the set of indicators used for university research assessment practices is likely to reinforce this trend. In Spain, for example, scientists have been assessed by an evaluation commission every six years since 1989 on the basis of what they consider their best scientific output for the period considered. Researchers are requested to justify the quality of their output according to several criteria, including the number of citations and quality of the journals in which they have published. In many research areas, the criteria accepted as quality indicators for an academic journal contain precisely the JIF and the inclusion of the journal in the ISI citation indexes (Bordons et al. 2002; Bordons and Gómez 2004). Since the ISI citation indexes hardly cover journals in Spanish" and "national journals, if covered, often show very low impact factor" (Bordons et al. 2002: 196), Spanish scientists have increasingly privileged publications in English in ISI-covered journals, and this had augmented the progressive marginalization of national journals. Between 1994 and 2001, for example, publications form the Spanish region of Madrid in the 
Spanish database ICYT (Science and Technology) decreased by $15 \%$, while publications in ISI Science Citation Index increased by 54\% (Bordons and Gómez 2004: 192).

It is worth stressing that it is likely that this effect is the result of the incentives built into the evaluation system, and not the outcome of an unalterable fate (cf. Section 2.1). Obviously, more empirical research would help to clarify the net effect of evaluation policies on the use of languages in scientific communication.

2.2.2. Bibliometric indicators in the Italian evaluation system. Bibliometric indicators play an important role in the new Italian system for university evaluation. First, they have to be taken into account by evaluation commissions in assessing applicant lecturers' profile. In practice, the "internationally acknowledged parameters" mentioned in Law No. 1/2009 (Art. 1.7) are, among others, the ISI-based JIF and the Hirsch-index ${ }^{13}$ (MIUR 2009b). This provision applies in the scientific domains in which the use of such indicators is internationally accepted, but no clear definition of these domains is provided.

Secondly, bibliometric indicators play a role, though more indirectly, in the procedures used for guiding the allocation of public funding on the basis of research and teaching performance (Art. 2, Law No. 1/2009). In this section I focus on indicators for the assessment of research quality, since they are more relevant from a language policy perspective.

There are four such indicators (MIUR 2009a). The first indicator (B1) is based on the rating received by universities and research centers (hereinafter "participant institutions") in the "Three-years Research Evaluation" (Valutazione Triennale della Ricerca, or VTR). The VTR was carried out between 2001 and 2003 by the Committee for the Evaluation of Research (Comitato di Indirizzo per la Valutazione della Ricerca, or CIVR), following the example of the British "Research Assessment Exercise" (RAE), which will be replaced by the "Research Excellence Framework" in the future. The final report was published in 2007 (CIVR 2007). Future research evaluations will be carried out by a new body, namely, the National Agency for the Evaluation of Universities and Research Institutes (Agenzia Nazionale di Valutazione del Sistema Universitario e della Ricerca - or ANVUR), which now replaces CIVR.

Indicator B2 is also based on the results of the VTR and it rewards initiatives aimed at exploiting results of applied research (e.g. patents). The third indicator (B3) refers to the percentage of researchers of the university or research centre having taken part in national research programs funded by MIUR. The fourth indicator (B4) refers to the capacity of a university to attract resources from European research projects. The weights of indicators in the evaluation of research quality are, respectively, 49\% for B1, 1\% for B2, 15\% for B3 and 35\% for B4. 
Let us focus on indicator B1. This indicator is computed on the basis on six sub-indicators, ${ }^{14}$ the most important of which is named "A". Sub-indicator A counts for 4/9 in the computation of $\mathrm{B} 1$, and it is based on ratings given by the evaluator to scientific output (or "product"). Participant institutions were requested to provide a sample of what, in their view, was the most significant scientific output (for example articles, books, book chapters, patents) produced by academic staff between 2001 and $2003 .{ }^{15}$ Some 151 independent panelists (Area panelists), distributed in 20 scientific areas, were responsible for the evaluation of these products. Panelists could rely on 6,661 external experts (Italian or foreign). Each product was evaluated by at least two external experts according to four criteria, namely, quality, importance, originality/innovation and internationalization.

On the basis of experts' rating and taking bibliometric indicators into account - in particular impact factor and citation analysis (CIVR 2003: 21) — panelists had to provide a synthetic quantitative rating for each product using the following weights: excellent, 1; good, 0.8; acceptable, 0.6; limited, 0.2. Notice that CIVR presents the JIF as an "objective" indicator (CIVR 2003: 6). Sub-indicator A is computed on the basis of these ratings. Has the JIF influenced panelists' ratings? Reale et al. (2008a) analyze the relationship between peer reviewers' rating of scientific output (in this case, articles in chemistry, biology, economics and statistics) and the impact factor of the journal in which articles have been published. They find the existence of a statistically significant causal and positive relationship between the JIF — the independent variable - and panelists' ratings - the dependent variable - (Reale et al. 2008a: 166). ${ }^{16}$ The authors conclude that the JIF, even slightly, has had an influence on ratings.

One could argue that the causal relationship between the JIF and ratings can be explained by the fact that both variables depend on a third variable, that is, intrinsic article quality. Obviously, this may be true. However, we still do not know how the JIF as such affects peer reviewers' perceptions, ${ }^{17}$ and the link between the "quality" of an article and the impact factor of a journal, as shown in Section 2.2.1, is still controversial.

Let us now turn to the role of the JIF in the procedures used in the VTR for selecting scientific output. Participant institutions autonomously select their products (the only restrictions being the number and the type of products). However, CIVR guidelines also provide that each selected scientific output must be accompanied by a note reporting, among other things, the "authority of the journal/editor/happening/etc. in which the product was publicised, including, if applicable, bibliometric indices (in particular impact factor and citation analysis)" (CIVR 2003: 18). The JIF, therefore, is implicitly singled out as information relevant for the evaluation, and this is confirmed by the fact that panelists have to take them into account for rating scientific products (see 
above). It is therefore not surprising that the JIF as such has often been used by participant institutions as criterion for selecting scientific products, especially in the hard science and technology areas (Reale et al. 2008b: 184-87). Since public funding is based on evaluation results, actors have an incentive to select the products according to the criteria which they think evaluators will reward.

\subsection{Discussion: the choice of research performance indicators as language policy}

Scientific output selected for the VTR 2001-2003 (CIVR 2007: 5) was in English in almost three fourths of cases (76\%), followed by Italian (22\%). Other languages play a marginal role ( $1 \%$ for French, $0.4 \%$ for German and $0.3 \%$ for Spanish). The use of English is more frequent in hard sciences (90\%) and economics $(80 \%)$, and less frequent in political science (approximately $30 \%$ ), the humanities (around 25\%) and law (less than 10\%). In addition, the use of English is more frequent in scientific areas in which the products selected are articles published in academic journals, in particular hard sciences and economics. The majority of products presented were articles, of which $94 \%$ were published in journals listed by ISI. No information is available as to whether the sample of products selected for the VTR is representative of the actual use of languages in the academic production in Italy.

The percentages just presented provide a useful point of departure to assess the future impact of this reform on the relative position of Italian and English in scientific communication. It would be risky to predict how actors will react to the reform, since there is no one-dimensional mode of reaction to indicators. ${ }^{18}$ Much will depend on the amount of resources invested to reward merits and on the policy and criteria adopted by ANVUR. Nevertheless, preliminary evidence suggests that the importance of bibliometric indicators based on the database of ISI will be strengthened in future evaluations carried out by ANVUR. ${ }^{19}$ In addition, the exact meaning of the criterion "internationalization" should be clarified. Finally, the presence of a clear language policy for managing linguistic diversity in peer reviewing will also play a role. Let us note that CIVR guidelines (CIVR 2003) include no provision on the management of linguistic diversity for those situations in which external experts are not able to read Italian. The uncertainty with respect to the capability of the evaluator to read the local language could discourage the selection of products in Italian, in particular if the evaluating institution gives the impression that it is generally advisable to present scientific output in English to ingratiate itself with non Italian-speaking reviewers.

Nevertheless, the example of countries such as Spain, which in 1989 adopted an evaluation approach similar to the VTR, seems to suggest that the use 
of ISI-based bibliometric indicators for evaluation purposes is likely to reinforce the role of English in primary scientific communication. This outcome, however, must not be regarded as a side or unintentional effect of the reform, but, on the contrary, as the result of "different mechanisms used implicitly and covertly to create de facto language policies" (Shohamy 2006: 57). ${ }^{20}$ This stresses the importance of incentives in language policy design, as opposed to binding regulation rules.

Obviously, this policy can entail both advantages and drawbacks. Generally speaking, the goal of an evaluator is to reward researchers publishing in the most competitive and prestigious international academic journals, to increase researchers' visibility and at the same time to counter scientific parochialism. These objectives are certainly sensible. Yet, the suitability of the tools chosen - that is, incentives linked to the value of the JIF and the choice of ISI citation indexes - with respect to ends is debatable. First, the validity of the JIF as a proxy for article "quality" is still very controversial and its use can have adverse effects (cf. Section 2.1), that is, actors may work with an eye on the value of indicator as such rather than on the result. Secondly, the question of language bias should be seriously addressed in international comparisons ${ }^{21}$ and in national research assessments. In order to have an accurate picture of universities' performance, evaluators should avoid procedures that could artificially penalize researchers or universities because of the language used in publications (I shall come back to this point in Section 4).

It is worth stressing that there is no necessary relationship between international visibility, language of publication and articles' quality. As Bordons et al. (2002: 203) note in the case of the hard sciences, claiming that national journals in languages other than English are of a lower quality is over-simplistic, since these journals often play an important role in the dissemination of research at a local level and they are particularly relevant for applied disciplines. The role of languages other than English in the process of creation, production and transmission of knowledge is an aspect that cannot be ignored in the knowledge-based economy. ${ }^{22}$

A separate but related issue concerns fairness in scientific communication. ${ }^{23}$ For reasons of space, it is not possible to discuss this question in detail. Even if the current pre-eminence of English in scientific communication is an historical phenomenon that is not necessarily entirely due to the evaluation policies that rely on indicators and citation indexed biased towards English, these policies end up strengthening this trend. As a result, they contribute to reinforcing the privileged position of Anglophone researchers and universities at the international level. Van Parijs (2007), for example, suggests that this problem could be tackled though appropriate redistributive policies at the international level, for example, by intervening in the domain of intellectual property rights. A possible policy could consist in making the access to scientific production in 
English (e.g. cost of subscription to academic journals) relatively cheaper for Universities in non-English-speaking countries. Let us note that, as Grin observes (2010), the conceptual difference between English and "English as a lingua franca" or ELF (e.g. Jenkins 2007) does not have any policy consequence in terms of fairness.

\section{The linguistic implications of international student mobility}

\subsection{Current policy trends in higher education}

International student mobility has become an increasingly significant global phenomenon. The number of tertiary-level students enrolled outside their country of citizenship has risen from 0.6 million in 1975 to 2.6 million in 2006, of which $83.5 \%$ were from countries of the OECD area (OECD 2008a: 352). International student mobility has always been promoted for fostering international cooperation, elite education and promoting intercultural dialogue. The emergence of the knowledge-based economy, however, has led policy makers to stress the strategic importance of policies aimed at attracting highly-skilled individuals and, in the case of EU, this has also led to several measures for removing barriers to the mobility of students and researchers (cf. Section 1).

The increase in international student mobility constitutes a challenge and a constraint for national educational systems, since "they have to adapt their curriculum and teaching methods to a culturally and linguistically diverse student body" (OECD 2008a: 350). One of the most remarkable effects related to the rise in international student mobility has been the increase in the number programs taught entirely in English (PTEs) - obviously, excluding programs in which English is the object of study - in many non-English-speaking countries, especially countries where the national language (or languages) is less commonly spoken worldwide.

Between 2002 and 2007, for example, the number of bachelors of arts (BA) and masters of arts (MA) programs taught entirely in English has tripled in absolute terms in 19 European countries, that is, the 15 members of the EU before the 2004 enlargement (excluding the UK, Ireland and Luxemburg), plus Iceland, Norway, Switzerland, the Czech Republic, Hungary, Poland and Slovakia (Wächter and Maiworm 2008: 31). The percentage of higher education institutions providing PTEs in these countries has increased from a range estimated at between $16 \%$ and $30 \%$ in 2002, to between 17 and $47 \%$ in 2007 . In the same group of countries the percentage of tertiary-level PTEs has increased from between $2 \%$ and $4 \%$ in 2002 to between $2.3 \%$ and $7.5 \%$ in 2007 , and the percentage of students attending PTEs has risen from between $0.2 \%$ and $0.5 \%$ 
in 2002 to between $0.6 \%$ and $1.8 \%$ in 2007 (Wächter and Maiworm 2008: $30-32$ ). The last percentage increases to between $0.7 \%$ and $2.1 \%$ if we enlarge the analysis to include all the current $27 \mathrm{EU}$ member states (with the exception of the UK, Ireland, Malta and Luxemburg) plus Iceland, Norway, Switzerland and Turkey (Wächter and Maiworm 2008: 28).

This section discusses the impact of reforms related to international mobility on languages used in teaching. I focus on two critical problems related to the increase of PTEs in the Italian university system, that is, the relationship between programs in Italian and programs in English, and the relationship between PTEs and the linguistic needs for foreign language skills in Italian firms.

\subsection{English-taught programs in Italian universities}

$10 \%$ of Italian universities offer at least a BA program taught entirely in English. ${ }^{24}$ This percentage climbs to $18 \%$ for MA, $44 \%$ for professionally-oriented post-graduate courses ("master" prior to the Bologna reform), and 31\% for $\mathrm{PhD}$ programs (Carfagna and Cavallini 2008: 4). The number of PTEs in Italy is still rather limited in absolute terms, but the provision of PTEs is on the rise, not only in areas such as economics and business, engineering, and hard sciences, but also in sociology and political science.

3.2.1. An additional or substitution role? Generally speaking and within certain limits, universities autonomously define the characteristics of programs offered, including the language used in teaching. However, an increase in the supply of PTEs is also explicitly supported by MIUR. In a letter to rectors of Italian universities concerning the possibility of denominating and carrying out courses in a foreign language, for instance, MIUR stated that "since it is part of the MIUR plans to improve and promote the internationalization of universities, [universities] are authorized, if suitable, to add programs named and carried out in a foreign language in the database of courses ['Banca dati Rad']" (1 February 2007, file no. 266).

It is still not clear whether the introduction of PTEs is intended to complement or act as substitute for programs in Italian, but some preliminary evidence suggests that, in absence of an explicit language policy, in several cases replacement could occur even at the BA level. The Polytechnic Institute of Turin, for example, since 2007, has eliminated two BA programs in Italian - namely, textile engineering and electronic and computer engineering - and replaced them with their equivalent in English. In addition, since 2007 the institute has adopted a systematic policy of encouraging Italian students to choose programs in English if programs are still available in both languages. Italian stu- 
dents attending BA programs in English do not have to pay tuition fees for the first year (between 365 and 2,445 EUR in 2011, depending on family income), whereas those attending programs in Italian have to.

More generally, limiting operating costs could lead some universities to avoid parallel programs in two languages in the long run. In other words, the gradual increase in the average level of citizens' proficiency in English resulting from current educational policy associated with the rising prestige of English are likely to affect future universities' strategies with respect to the languages to be used in teaching. Why should universities provide the same programs in two languages, if by adopting an English-only policy, especially at $\mathrm{MA}$ and $\mathrm{PhD}$ level, they can target both the international and the domestic student market?

At present, however, MIUR has adopted no specific language policy aimed at managing in an integrated way the effects of an increase of PTEs on the local linguistic environment. Two issues in particular are not addressed. A first issue concerns the access to higher education in those geographical areas where programs in Italian are abolished. Students who are not proficient in English or who want to study in the national language might be obliged de facto to move to a different region to find similar programs still available in Italian and therefore bear considerable adjustment costs. Secondly, MIUR should assess the systemic effect in the long run of a gradual shift to English in teaching. In other words, the aggregate effect of short-term strategies adopted by individual universities that for some reason invest in programs exclusively in English (cf. Section 3.3) may not be compatible with society's objective of avoiding "domain loss" in certain disciplines, that is, preserving in the long run the functions of the local language as a language of advanced culture and learning.

3.2.2. PTEs and economic activity. The increase of PTEs can also be assessed with respect to the current demand for skills in foreign languages in the labor market. The literature provides very few theoretical models and empirical analyses of the relationship between the demand for foreign languages and business activities. ${ }^{25}$ However, several useful insights can be derived also from a descriptive analysis of census data or similar large-scale surveys.

As shown in Table 1, the Italian economy is characterized by a predominance of micro- and small-sized companies. Together they account for $99.4 \%$ of all Italian firms, they absorb $69 \%$ of the total workforce, and they produce $56.4 \%$ of the total added value.

In 2005-2006 the Italian Minister of Labor carried out a survey on the demand and supply for linguistic education and training in Italy. As regards businesses, the survey analyses a sample of 1,616 businesses with at least 2 employees (Ministry of Labour 2006: Ch. 2.2). Unfortunately, the classes of 
Table 1. The structure of Italian firms, 2006-2007*

\begin{tabular}{llccc}
\hline $\begin{array}{l}\text { Class of firms according to the number of } \\
\text { employees }\end{array}$ & $\begin{array}{l}\text { Micro } \\
(1-9)\end{array}$ & $\begin{array}{l}\text { Small } \\
(10-49)\end{array}$ & $\begin{array}{l}\text { Medium } \\
(50-249)\end{array}$ & $\begin{array}{l}\text { Large } \\
\text { (More than } \\
250)\end{array}$ \\
\hline $\begin{array}{l}\text { Percentage of firms belonging to a given class } \\
\quad \text { year 2007) }\end{array}$ & $94.8 \%$ & $4.6 \%$ & $0.5 \%$ & $0.1 \%$ \\
$\begin{array}{l}\text { Percentage of total Italian workforce employed } \\
\text { in a given class of firms (year 2007) }\end{array}$ & $47.6 \%$ & $21.4 \%$ & $12.7 \%$ & $18.3 \%$ \\
$\begin{array}{l}\text { Share of the added value produced in Italy in } \\
\text { 2006 by class of firms }\end{array}$ & $33.9 \%$ & $22.5 \%$ & $16.1 \%$ & $27.5 \%$ \\
\hline
\end{tabular}

*Source: table compiled by the author on the basis of ISTAT (2009: 70-71)

firms analyzed differ from those used by the Italian Institute of Statistics (ISTAT). Firms have been classified in three classes, namely, micro businesses (from 2 to 9 employees), ${ }^{26}$ small and medium-sized businesses (SMB, from 10 to 99 employees), and large businesses (100 or more employees). $70.2 \%$ of the firms interviewed are micro businesses, $22 \% \mathrm{SMB}$, and $7.8 \%$ large businesses. In the rest of this section, therefore, I will refer to the classes adopted by the Ministry of Labor.

Italian firms are mostly oriented towards the domestic market: $80.7 \%$ of micro businesses, $52.4 \%$ of SMBs and $40 \%$ of large businesses do not participate in actions involving exposure to foreign countries (e.g. import, export, delocalization initiatives, participation in trade fairs or joint ventures). ${ }^{27}$ Businesses involved in exports operate mainly within Western Europe, and in particular sell to Germany and France, followed by Spain and the UK (ICE 2009: 37). In $47 \%$ of cases, the percentage of sales due to exports with respect to the total business turnover is less than $20 \%$.

Let us turn to data on language practices. $56.4 \%$ of businesses do not employ any person who uses foreign languages in the workplace. The remaining firms $(43.6 \%)$ usually employ a limited number of personnel with knowledge of foreign languages (no more than two employees per company in $70 \%$ of cases, with obvious differences between SMBs and large firms). If foreign languages are used, the most often used languages are English (71.9\%), German (20.6\%) and French (17.6\%) (more than one answer to this questionnaire item was possible).

$67 \%$ of businesses do not intend to invest in foreign language education in the next two years (base year 2005-2006), and 20\% are not likely to invest. Only $4.6 \%$ of Italian firms have organized courses of foreign languages in the last two years or taken measures for developing or improving the linguistic competence of their staff ( $43.1 \%$ for large companies). Micro businesses and SMBs that have organized language training have focused mainly on English. Large companies are more likely to diversify their language training, and be- 
sides English (99.6\% of companies that have provided linguistic education to staff), they also provide training in French (20.6\%), German (14.4\%) and Spanish (10.5\%). The majority of companies providing language training for their staff focuses on courses for beginners.

The relatively modest role of foreign languages in Italian businesses is confirmed by results concerning citizens' use of foreign languages (Ministry of Labor 2006: Ch. 2.1). Only $31 \%$ of citizens who know at least one foreign language use it in the workplace. Notice, however, that this figure is computed on a sample also including people who do not work. If we restrict the sample to those who work and know at least one foreign language, $40 \%$ of interviewees declare that they have used foreign languages in their professional activities.

It is worth repeating that more data and theoretical models would be necessary to provide a more accurate picture of the relationship between economic activities and languages. However, on the basis of data available, it emerges that the Italian economy is characterized by a predominance of micro and small or medium-sized businesses operating mainly on the domestic market and in the local language. In many cases, especially in micro businesses and SMBs, a minimal competence in foreign languages, if necessary, is considered sufficient (Ministry of Labor 2006: 69). The knowledge of English is certainly a very important skill, but the acquisition of a technical-scientific repertoire in Italian, generally speaking, remains necessary for operating effectively in the Italian economy both for local and foreign students.

Clearly, these data reflect the present picture of the Italian economy, and this situation could change in the future. One could also argue that PTEs could contribute to "internationalizing" the domestic economy. However, this argument is not fully convincing, since the generally low demand for foreign languages skills is the result and not the cause of a relatively low level of international activities of Italian businesses. Only $0.6 \%$ and $2.1 \%$ of firms state that lack of language skills has been respectively a strong or partial factor in explaining the absence of international activities. Hence, given the current context, the actual relevance of an unconditional support to programs exclusively in English from the BA level is open to question. On the contrary, given the current relatively low level of fluency in foreign languages in the population, this could raise new linguistic barriers and therefore negatively affect the access to higher education. ${ }^{28}$

A further point which is often not duly taken into account concerns the role of languages other than English in businesses, in particular in large companies. Data just presented show that the demand for skills in foreign languages in Italy is more diversified than what is usually believed (this is probably related to the fact the most important trading partners of Italian businesses are European countries, in particular Germany, France and Spain). Surveys carried out in the EU (CILT 2006) and in Switzerland (Grin et al. 2010) tend to confirm 
and generalize this result. At the European level, for example, the sum of demand for skills in languages other than English (e.g. German, Spanish, French, Chinese, Arabic, etc.) is greater than the demand for English itself, both for SMB and large companies (CILT 2006: 44-45). The development of multilingual repertoires (also technical-scientific), therefore, can be a strategic asset for students.

\subsection{Discussion: student mobility and academic performance indicators}

To my knowledge, no official data are available regarding the current demand by students for PTEs in Italy. However, figures available for Europe tend to show that the demand by domestic students has not played a central role in explaining the introduction of PTEs, which has been mostly a top-down rather than a bottom-up process.

According to Wächter and Maiworm (2008: 70-71), initiatives and support for the introduction of PTEs in continental European countries have typically been derived from international offices $(77 \%)$, deans of faculties and departments $(77 \%)$, and presidents, rectors, vice-presidents or vice-rectors $(76 \%)$, while individual students and/or student organizations are at the bottom of the list $(27 \%)$ (more than one answer to this questionnaire item was possible). No data are available regarding the demand for PTEs from firms. In addition, Wächter and Maiworm (2008: 68) report that according to institutional coordinators in the faculties and departments of European universities, the introduction of PTEs is mainly justified in terms of need for (i) attracting foreign students in general (84\%), (ii) making domestic students fit for the global/ international markets $(84 \%)$, and (iii) sharpening the profile of the institution $(70 \%)$ - more than one answer was possible. Data related to the opinion of program directors are similar, that is, $81 \%$ for reason (i), $75 \%$ for (ii) and $75 \%$ for (iii).

Notice, however, that the second answer "appears somewhat astonishing, given that [on average] only 35\% of all students enrolled in English-medium programs are of domestic origin" (Wächter and Maiworm 2008: 67). Hence, these data would suggest that it is more likely that in several cases BA and MA degrees taught entirely in English should be regarded more as a "signal of internationalization" given by universities than a response to demand by domestic students for PTEs, or to a demand for a specific linguistic profile in the labor market (cf., for example, data for Italy in Section 3.2.2). Clearly, attending courses taught in a foreign language can contribute significantly to increasing linguistic skills, but the point is to understand the clear relation between fitness for the domestic or global job market and the language used in teaching (as opposed to language taught as a subject). 
In other words, attracting foreign students has become an end in itself. This is probably not only due to the need for attracting the "brightest students" from abroad (cf. Section 1), but also because indicators related to the number of foreign students as such are often considered indicators of quality of a university, or more precisely its international attractiveness and prestige (cf. also justification (iii) mentioned above). The "percentage of foreign students with respect to total enrolments", for example, is used as an indicator of quality of universities in one of the most popular world rankings of universities, namely, the ranking of the Times Higher Education Supplement. Let us note that the impact of international rankings on universities' strategies should not be underestimated (Van Parijs 2009; Weingart 2005). In France, for example, 83\% of directors of higher education institutions ("universités" and "grandes écoles") declare that they have taken concrete steps to improve the position of their institution in international rankings (Bourdin 2008: 99).

The underlying assumption behind this indicator is that the "best" universities attract more students from other countries. However, this indicator is not valid (see Section 2.1) for several reasons. First, foreign students may be attracted because programs are easier than in universities in their own country or other prestigious foreign universities, by the lack of access to university in the desired field in their own country, or simply by lower tuition fees. For example, lower tuition fees is one of the arguments used by Dutch universities to attract British students in the Netherlands (Hodge 2009). Secondly, and more importantly, student mobility patterns are heavily influenced by linguistic variables. International mobility is easier between neighbor countries sharing the same language, since "statistics suggest that, all other things being equal, students would choose culturally and linguistically similar home and educational contexts" (Hughes 2008: 10). In addition, the students' choices are influenced also by the languages they have learned in their home country and/ or by the wish to improve their language skills through immersion and study abroad (OECD 2008a: 355). This translates into a key competitive advantage especially to English-speaking countries (and to a certain extent also to French and German-speaking countries) (Hughes 2008; OECD 2008a: 355), and it again raises the question of fairness in scientific communication (cf. Section 2.3). As Hughes notes, the dominance of Anglophones institutions on the global education market "leads to practical and ethical questions at a variety of levels. At country level it can be argued that non-English speaking countries find it difficult to compete in terms of the benefits of higher education internationalization — the market is simply skewed against them" (Hughes 2008: 9).

Clearly, factors influencing language policies in higher education are manifold, and it is often very difficult to tell whether PTEs are an actual response to a demand for specific linguistic skills by firms, an effective immigration 
policy, or a marketing strategy to increase universities' visibility or to artificially boost its position in international rankings (note that this is a second example of adverse effect - cf. Section 2.1). Generally speaking, increasing the supply of PTEs can give rise to several advantages, for example a broadening of the range of education programs or a higher inflow of students from other countries. Nevertheless, depending on the language policy adopted, they can also entail a decrease in linguistic diversity in education or a questionable unequal treatment of students as in the case of the Polytechnic Institute of Turin. In this section, I have shown that these drawbacks are usually not sufficiently and critically characterized in Italy, and that the advantages are sometimes assumed rather than proved.

\section{Concluding remarks}

This article provides a critical assessment of the impact on scientific communication of tools and procedures chosen for research evaluation and for promoting international student mobility in Italy. The emergence of the knowledge-based economy constitutes an appropriate framework to understand the reform processes occurring in the Italian university and their linguistic consequences, but this should not conceal the active role of States in influencing the pace and modalities of change, and therefore their responsibility as (language) policy makers.

As regards the evaluation of research activities, for example, the decision to rely on tools and procedures based on ISI-based bibliometric indicators, both when recruiting lecturers and evaluating scientific products ex post, is not imposed by context, but represents a deliberate policy choice. I have shown that the current use of bibliometric indicators as academic performance indicators can create a set of incentives fostering de facto the position of English in scientific communication. In principle, if the policy makers had wanted to take language bias into account and perhaps to correct it, they could have relied on more multilingual databases or alternatively they could have decided to allocate part of the resources on the basis of a bibliometric analysis carried out on journals in the national language only.

Similarly, there is no univocal way to promote international student mobility. Section 3 shows that the "internationalization" of Italian universities is often hastily (and perhaps normatively) interpreted as synonymous with English-medium education, also as a result of the implicit or explicit use of "number of foreign students" as an international indicator of academic performance. As a result, questions related to access to higher education, domain loss and the current needs for linguistic skills on the job market have not been addressed properly. 
Since the choice of academic performance indicators does not necessarily have the same outcomes in terms of actors' behavior, including language choices, it is the responsibility of the policy maker to carry out an accurate identification and comparison between the relative advantages and drawbacks of different choices, including their consequences in terms of fairness and impact on linguistic diversity. I have shown that the linguistic implications of the reforms recently introduced in Italy often have not been properly characterized and taken into account.

This article has focused on Italy, but its general results may also be relevant to other countries, and the EU as a whole. Let us note, for example, that the European Commission has stressed that the creation of a common European research area requires public authorities and research institutions "to work to remove the legal, administrative and practical (e.g. linguistic) barriers to geographical and inter-sectoral mobility [or researchers]" (European Commission 2007: 11, my emphasis).

Humboldt-Universität zu Berlin, Germany

Université de Genève, Switzerland

Correspondence address: gazzola@hu-berlin.de

\section{Appendix: List of abbreviations}

ANVUR National Agency for the Evaluation of Universities and Research Institutes

CIVR Committee for the Evaluation of Research

EU European Union

ISI Institute for Scientific Information

JIF Journal impact factor

MIUR Minister of Education, University and Research

OECD Organisation for Economic Co-operation and Development

PTEs Programs taught entirely in English

RAE Research Assessment Exercise

SMB Small and medium-sized businesses

VTR Three-years Research Evaluation

VQR Evaluation of Research Quality

\section{Notes}

* The author wishes to thank François Grin, Hartmut Haberland, Janus Mortensen, Tom Ricento and François Vaillancourt for very useful comments and remarks. I also thank the 
CALPIU Research Center for its financial support. Any errors and all interpretations are all my own.

1. Lack of space precludes a critical discussion of the concept of "knowledge-based economy". For a critique see Bull (this issue) and Williams (2010).

2. For a discussion of the relationships between the EU strategy for higher education and the knowledge-based economy, see in particular Fairclough and Wodak (2008) and European Commission (2007).

3. For example, in the period $1997-2001$, Italy counted for $4.3 \%$ of "top $1 \%$ highly cited publications", as opposed to $12.8 \%$ for the UK, 10.4\% for Germany and 6.9\% for France (Buzzetti and Gioia 2007: 24). Besides, Italy receives only $1.7 \%$ of the world's foreign students, as opposed to $11.3 \%$ for the UK, $8.9 \%$ for Germany and $8.5 \%$ for France (OECD 2008a: 353).

4. On the distinction between primary and secondary scientific communication see Carli and Calaresu (2007).

5. In the Italian system the term "ricercatore" corresponds to the first university position in the hierarchy, and it is more or less equivalent to "lecturer" in the British system or "assistant professor" in the North American one. In this article, to avoid ambiguities, I will use the term "lecturer" for "ricercatore", and "researcher" or "scientist" to denote the academic staff more generally.

6. See Archambault and Larivière (2009) and Moed (2005: Ch.1) for a history of the JIF.

7. On the JIF see, among others, Archambault and Larivière (2009), Merlet et al. (2007), Moed (2005), Weingart (2005), Amin and Mabe (2000) and Seglen (1997).

8. At the time of writing, Thompson Reuters is developing new indicators to overcome some of these shortcomings, such as a five-year impact factor, the Eigenfactor and the Journal "Self Citations" indicator (see http://www.thomsonreuters.com/content/press_room/sci/350008, accessed on 21January 2011). However, any reference to their work can only be provisional.

9. The ratio CPP/FCSm is defined as follows: CPP (Citation per Publication) is equal to $\mathrm{C}(\mathrm{g}) / \mathrm{P}(\mathrm{g})$. FCSm (Field Citation Score) is equal to $\mathrm{C}(\mathrm{f}) / \mathrm{P}(\mathrm{f}) . \mathrm{P}(\mathrm{g})$ is the number of publications in internationally refereed journals covered by citation indexes in a given field made by researchers of a country $(\mathrm{g}) . \mathrm{C}(\mathrm{g})$ is the number of citations to these publications. $\mathrm{P}(\mathrm{f})$ is the number of publications in international journals covered by citation indexes in a given field (f) made by all researchers in the world. C(f) is the number of citations to these publications. Self-citations are excluded. The CPP/FCSm indicator, therefore, is the ratio between the impact of publications of a specific entity "g" (e.g., country or faculty) - CPP — and a worldwide impact mean - FCSm.

10. See, for instance, Perotti (2008: 46).

11. Cf. Sandelin and Sarafoglou (2004).

12. Notice that publications in Spanish in the ISI Science Citation Index Expanded fell from $0.7 \%$ in 1980 to $0.4 \%$ in 1990 and $0.3 \%$ in 2000 (Bordons and Gómez 2004: 189).

13. The Hirsch-index, or $h$, is defined as follows: the value of $h$ is equal to the number of articles (N) written by an author that have $\mathrm{N}$ or more citations. For a critique of the validity of the H-index, see Merlet et al. (2007) and Gingras (2008).

14. These sub-indicators are aimed at assessing, among other things, participant institutions' capacity to use their own resources for research projects, their involvement in the international mobility of researchers and their post-graduate education activities (CIVR 2007: 2)

15. For technical details see CIVR (2007). See also Reale (2008) for a meta-evaluation of the VTR.

16. The authors use the "Ordered Logit Model", a regression model for ordinal dependent variables (in this case, panelists' ratings).

17. Franceschet and Costantini (2011) have founded a positive (but not perfect) correlation between the JIF and panelists' ratings in the VTR. The authors, however, note that during the 
VTR panelists had access to the impact factors of journals in which the assessed articles were published.

18. In technical terms, we refer to "incentive compatibility constraint", that is, incentives such that actors prefer to act in accordance with the incentives provided.

19. See the guidelines for the "Evaluation of Research Quality" (Valutazione della Qualità della Ricerca or VQR) on www.anvur.org, accessed on 8 October 2011. The VQR concerns the evaluation of research activities carried out by Italian universities or research institutes from 2004 to 2010 . The VQR will be carried out in 2012.

20. Obviously, the concept of de facto language policy raises the issue of policy maker's intentionality.

21. Several indicators used in the "Academic Ranking of World Universities" produced by the Shanghai Jiao Tong University, for example, are based exclusively on the ISI databases (Liu and Cheng 2005).

22. Cf. Carli and Calaresu (2007) and Ehlich (2004) for a critical assessment of the need for a "universal" language for science. On the analytical groundlessness of the assumption that the most efficient solution for scientific communication is always to operate in a single language, see Gazzola and Grin (2007).

23. Cf. various contributions in Carli and Ammon (2007).

24. In absolute terms this is equivalent to 8 of the 77 legally recognized universities, excluding distance-learning universities.

25. Cf. Grin et al. (2010). See also CILT (2006).

26. It is worth noting that the survey does not take into account businesses with only one employee (which counts for almost $60 \%$ of Italian firms), because otherwise small, mediumsized and large businesses would have been too penalized in case of proportional distribution over the total. Results, therefore, tend to over represent both SMB and large business.

27. Data quoted have been derived by the author from the original survey database (www.letitfly. it). The majority of figures, however, are also available in Ministry of Labor (2006).

28. Although $87.7 \%$ of Italian citizens aged $15-24$ and $59.5 \%$ of those aged $25-44$ declare to know (at least) English, those declaring to have a very good command of it are still a small minority (respectively, $7.1 \%$ and $6 \%$ ).

\section{References}

Amin, Mayur \& Michael Mabe. 2000. Impact factors: use and abuse. Perspectives in Publishing 1. 1-6.

Ammon, Ulrich. 2006. Language planning for international scientific communication: an overview of questions and potential solutions. Current Issues in Language Planning 7(1). 1-30.

Archambault, Éric \& Vincent Larivière. 2009. History of the journal impact factor: contingencies and consequences. Scientometrics 79(3). 635-649.

Bordons, María, María Teresa Fernández \& Isabel Gómez. 2002. Advantages and limitations in the use of impact factor measures for the assessment of research performance in a peripheral country. Scientometrics 53(2). 195-206.

Bordons, María \& Isabel Gómez. 2004. Towards a single language in science? A Spanish view. Serials 17(2). 189-195.

Bourdin, Joël. 2008. Rapport d'information sur le défi des classements dans l'enseignement supérieur. Report no. 442. Paris: French Senate.

Bracho-Riquelme, Rodolfo L., Nazario Pescador-Salas \& Miguel Arturo Reyes-Romero. 1999. The change from French to English and its effect upon the impact factor and ranking of the Pasteur journals. Journal of Information Science 25(5). 413-417. 


\section{M. Gazzola}

Buzzetti, Giuliano \& Isabella Maria Gioia. 2007. I numeri della ricerca scientifica in italia. In Tommaso Maccacaro (ed.), La ricerca tradita, 11-36. Milan: Garzanti.

Carfagna, Massimo \& Marina Cavallini. 2008. Survey on education provision in English language in Italian universities, year 2007. Rome: Conference of the Rectors of Italian Universities (CRUI).

Carli, Augusto \& Ulrich Ammon. 2007. Linguistic inequality in scientific communication today. AILA [Association Internationale de Linguistique Appliquée] Review 20 [Special issue].

Carli, Augusto \& Emilia Calaresu. 2003. Le lingue della comunicazione scientifica. La produzione e la diffusione del sapere specialistico in italia. In Ada Valentini, Piera Molinelli, Pierluigi Cuzzolin \& Giuliano Bernini (eds.), Ecologia linguistica. Atti del $36^{\circ}$ congresso internazionale di studi della Società linguistica italiana, 27-74. Rome: Bulzoni.

Carli, Augusto \& Emilia Calaresu. 2007. Language and science. In Marlis Hellinger \& Anne Pauwels (eds.), Handbook of language and communication: diversity and change, 523-552. Berlin $\&$ New York: Mouton de Gruyter.

CILT. 2006. Elan: effects on the European economy of shortages of foreign language skills in enterprise. London: CILT, the National Centre for Languages.

CIVR. 2003. Guidelines for research evaluation. Rome: Commitee for the Evaluation of Research (CIVR).

CIVR. 2007. VTR 2001-2003. Relazione finale. Rome: Commitee for the Evaluation of Research (CIVR).

Ehlich, Konrad. 2004. The future of German and other non-English languages of academic communication. In Andreas Gardt \& Bernd Hüppauf(eds.), Globalization and the future of German, 173-184. Berlin \& New York: Mouton de Gruyter.

European Commission. 1999. Selection and use of indicators for monitoring and evaluation, Vol. 2, Means collection - evaluation of socio-economic programs. Luxembourg: Office for Official Publications of the European Communities.

European Commission. 2007. Green paper. The European research area: new perspectives. Brussels: European Commission.

Fairclough, Norman \& Ruth Wodak. 2008. The Bologna process and the knowledge-based economy: a critical discourse analysis approach. In Bob Jessop, Norman Fairclough \& Ruth Wodak (eds.), Higher education and the knowledge based economy in Europe, 109-126. Rotterdam: Sense Publishers.

Franceschet, Massimo \& Antonio Costantini. 2011. The first Italian reseach assessment exercise: a bibliometric perspective. Journal of Informetrics 5(2). 275-291.

Fuyuno, Ichiko \& David Cyranoski. 2006. Cash for papers: putting a premium on publication. Nature 441(7095). 792.

Gazzola, Michele \& François Grin. 2007. Assessing efficiency and fairness in multilingual communication: towards a general analytical framework. AILA [Association Internationale de Linguistique Appliquée] Review 20. 87-105.

Gingras, Yves. 2008. La fièvre de l'évaluation de la recherche. Du mauvais usage de faux indicateurs. 2008-05, Note de recherche. Montreal: Interuniversity Research Centre on Science and Technology (CIRST).

Grin, François. 2010. La temptació de l'oligarquia i els seus perills. In Palomero, Josep (ed.), Proceedings of the International Symposium on "Situació I perspectives del plurilingüisme a Europa”, 6-8 November 2008, 71-80. Valencia: Valencian Academy of Language. (Also available as The oligarchic temptation and its dangers. ELF Working Paper 7. Observatory "Economics-Languages-Training" (ÉLF). University of Geneva. www.elf.unige.ch, accessed on 21 January 2011). 
Grin, François, Claudio Sfreddo \& François Vaillancourt. 2010. The economics of the multilingual workplace. London: Routledge.

Hodge, Lucy. 2009. Go Dutch, save money. The Independent (Education), 18 June.

Hughes, Rebecca. 2008. Internationalisation of higher education and language policy: questions of quality and equity. Higher Education Management and Policy 20(1). 1-18.

ICE. 2009. L'Italia nell'economia internazionale. Sintesi del rapporto ICE 2008-2009. Rome: Italian Institute for Foreign Trade (ICE).

ISTAT. 2009. Rapporto annuale. La situazione del Paese nel 2008. Rome: Italian Institute of Statistic (ISTAT).

Jenkins, Jennifer. 2007. English as a lingua franca: attitude and identity. Oxford: Oxford University Press.

Liu, Cai Nian \& Ying Cheng. 2005. The academic ranking of world universities. Higher Education in Europe 30(2). 127-136.

Maccacaro, Tommaso (ed.). 2007. La ricerca tradita. Milan: Garzanti.

Merlet, Jean-Pierre, Anne-Marie Kermarrec, Luc Segoufin, Erwan Faou \& Philippe Robert. 2007. Que mesurent les indicateurs bibliometriques? Document d'analyse de la commission d'évaluation de l'INRIA Paris: National Research Institute for Information and Automation Technology (INRIA).

Ministry of Labor. 2006. La domanda e l'offerta di formazione linguistica in Italia [The supply and demand for linguistic education in Italy]. Rome: Ministero del Lavoro e della Previdenza Sociale (Italian Ministry of Labor).

MIUR. 2009a. Decreto criteri di ripartizione del fondo di finanziamento ordinario (FFO) delle università per l'anno 2009 (Ministerial decree 23 September, N. 45/2009). Italian minister of education, university and research (Miur), Rome.

MIUR. 2009b. Valutazione dei titoli e delle pubblicazioni scientifiche (Ministerial Decree 28 July 2009 N. 89/2009). Italian minister of education, university and research (Miur), Rome.

Moed, Henk F. 2002. Measuring China's research performance using the Science Citation Index. Scientometrics 53(2). 281-296.

Moed, Henk F. 2005. Citation analysis in research evaluation. Dordrecht: Springer.

OECD. 1996. The knowledge-based economy Paris: Organisation for Economic Co-operation and Development (OECD).

OECD. 2008a. Education at a glance 2008, OECD Indicators. Paris: Organisation for Economic Cooperation and Development (OECD).

OECD. 2008b. The global competition for talent: mobility of the highly skilled. Paris: Organisation for Economic Cooperation and Development (OECD).

Perotti, Roberto. 2008. L'università truccata. Turin: Einaudi.

Reale, Emanuela (ed.). 2008. La valutazione della ricerca pubblica. Un'analisi della valutazione triennale della ricerca. Milan: FrancoAngeli.

Reale, Emanuela, Riccardo Palumbo, Antonio Costantini \& Marco Costantini. 2008a. La valutazione dei pari. In Emanuela Reale (ed.), La valutazione della ricerca pubblica. Un'analisi della valutazione triennale della ricerca, 148-179. Milan: FrancoAngeli.

Reale, Emanuela, Paolo Sacchetta, Anna Barbara, Antonio Costantini \& Marco Seeber. 2008b. Il processo del VTR: dalla selezione dei prodotti alla valutazione. In Emanuela Reale (ed.), $L a$ valutazione della ricerca pubblica. Un'analisi della valutazione triennale della ricerca, 180-212. Milan: FrancoAngeli.

Sandelin, Bo \& Nikias Sarafoglou. 2004. Language and scientific publication statistics. Language Problems \& Language Planning 28(1). 1-10.

Seglen, Per O. 1997. Why the impact factor of journals should not be used for evaluating research. British Medical Journal 314(7079). 498-502. 


\section{M. Gazzola}

Shohamy, Elena. 2006. Language policy. Hidden agendas and new approaches. London: Routledge.

Tabellini, Guido. 2007. Ricerca e sviluppo economico. In Tommaso Maccacaro (ed.), La Ricerca tradita, 83-100. Milan: Garzanti.

Van Leeuwen, Thed N., Henk F. Moed, Robert J. W. Tijssen, Martijn S. Visser \& Anthony F. J. Van Raan. 2001. Language biases in the coverage of the Science Citation Index and its consequences for international comparisons of national research performance. Scientometrics 51(1). 335-346.

Van Parijs, Philippe. 2007. Tackling the Anglophones' free ride: fair linguistic cooperation with a global lingua franca. AILA [Association Internationale de Linguistique Appliquée] Review 20. $72-86$.

Van Parijs, Philippe. 2009. European higher education under the spell of university rankings. Ethical Perspectives 16(2). 189-206.

Van Raan, Anthony F. J., Thed N. Van Leeuwen \& Martijn S. Visser. 2011. Severe language effect in university rankings: particularly Germany and France are wronged in citation-based rankings. Scientometrics 88(2). 495-498.

Wächter, Bernd \& Friedhelm Maiworm. 2008. English-taught programs in European higher education. The picture in 2007. Bonn: Lemmens.

Weingart, Peter. 2005. Impact of bibliometric upon the science system: inadvertent consequences? Scientometrics 62(1). 117-131.

Williams, Glyn. 2010. The knowledge economy, languages and culture. Bristol: Multilingual Matters. 